\title{
A privatização da educação no contexto do golpe institucional no Brasil
}

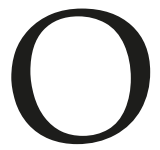
golpe político/jurídico/midiático no Brasil, em 2016, teve como principal característica reordenar o país às políticas neoliberais (Estado Mínimo), com prevalência do projeto da elite nacional de entregar as riquezas da nação ao capital internacional e de se apropriar dos recursos públicos para si, alimentando o histórico processo de patrimonialismo, hoje travestido de intensa privatização dos serviços públicos.

A educação, assim como a saúde, a previdência pública e outras áreas sociais tem sofrido sistemático processo de privatização ao longo de décadas, o qual tende a se agravar com as medidas já implementadas pelo governo golpista e de outras que estão no horizonte do empresariado e de financistas nacionais e internacionais (verdadeiros donos do sistema político corrompido em nosso país!).

O projeto neoliberal impõe a mercantilização da educação e de vários outros serviços públicos no Brasil e no mundo. Em 2014, as despesas correntes e os investimentos educacionais somaram 6,2\% do PIB, sendo, portanto, um "mercado" bastante promissor para os investidores nacionais e internacionais.

Diferentemente da década de 1990, quando o alvo principal do projeto neoliberal era a privatização das universidades públicas, o objetivo do mercado agora avança para a escola de nível básico (da creche ao ensino médio, incluindo a formação técnica e profissional), além da ampliação do ensino superior privado, através de volumosos subsídios governamentais para financiamento de vagas. Esses subsídios, por sua vez, ocorrem por meio de empréstimos diretamente aos estudantes, pelo pagamento de bolsas de estudos às instituições e pela compensação ou desoneração de impostos às universidades privadas.

Já o ataque à universidade pública passou a ser mais intenso após a aprovação de diversas políticas de cotas raciais e sociais, que privilegiaram a presença de estudantes oriundos das escolas públicas, de famílias pobres e de etnias negra, parda e indígena nas instituições públicas. As cotas interferiram significativamente na presença da classe média e alta nas universidades públicas e acabaram sendo o estopim para o ataque ao ensino superior público, que mantém um nível de excelência ainda muito acima da maioria das universidades privadas, seja na graduação, seja em atividades de pesquisa e extensão. 
Após a consumação do golpe institucional, a nova gestão do Ministério da Educação cortou em média $30 \%$ dos orçamentos das universidades públicas, comprometendo as despesas correntes e a manutenção e expansão de turmas de graduação e pós-graduação. O objetivo do governo golpista consiste em intensificar o processo de sucateamento das universidades, abrindo caminho para a privatização. Com isso, sucumbem-se as metas de expansão de vagas no ensino superior público, previstas no Plano Nacional de Educação (Lei 13.005, PNE), aprovado em 2014.

Note-se que o projeto do golpe visa claramente atingir a soberania nacional, restringindo o acesso ao ensino superior público e comprometendo os compromissos do Estado em formar novos mestres e doutores - base para o desenvolvimento social, econômico e tecnológico da nação. No Brasil, a pós-graduação é majoritariamente ofertada por instituições públicas, enquanto que a graduação é predominantemente privada - e o PNE pretendia inverter a lógica de acesso à graduação, ampliando as matrículas públicas.

Nos últimos anos, a educação básica passou a sofrer intenso ataque do projeto de mercantilização, tanto na estrutura financeira-organizacional dos sistemas de ensino e das escolas, como na concepção curricular.

Para adentrar nesse tema, é preciso apresentar brevemente o principal instrumento de reforma do Estado aprovado pelo governo golpista no Congresso Nacional, qual seja, a Emenda Constitucional (EC) n. 95, que também abarca o ensino superior e outras políticas públicas.

A EC 95, que introduziu os artigos 106 a 114 no Ato das Disposições Constitucionais Transitórias (ADCT) da Constituição Federal (CF), congela as despesas correntes e os investimentos sociais da União com educação, saúde, previdência, segurança, habitação etc, por um período de 20 anos. Ou seja: nas próximas duas décadas as despesas sociais terão como teto (limite) somente a reposição inflacionária do ano anterior. Está proibido pela Constituição, o aporte de novos recursos provindos da receita corrente líquida (RCL) de impostos da União ao orçamento do MEC, até mesmo para se atingir a meta 20 do PNE, que prevê alcançar até 2024 o percentual de investimento na educação equivalente a $10 \%$ do Produto Interno Bruto (PIB).

E para que esse ajuste fiscal não corra riscos, a EC 95 suspendeu, também por duas décadas, o repasse de receitas constitucionais da União vinculadas à educação e à saúde (artigos 198 e 212 da CF).

Desde 1988, com a promulgação da Constituição pós-Golpe civil-militar, a União aplica, anualmente, nunca menos de 18\% e os Estados, o Distrito Federal e os Municípios $25 \%$, no mínimo, de suas receitas resultantes de impostos na manutenção e desenvolvimento do ensino. E com a EC 95, os repasses para a educação e a saúde, na esfera federal e nos entes subnacionais que adotarem medida similar de ajuste fiscal ao implementado pela União, ficarão limitados ao teto inflacionário, ainda que a receita de impostos supere a inflação até 2036. 
Estudos preliminares (e conservadores), a exemplo do documento publicado pelo Movimento Todos pela Educação, indicam que somente o Ministério da Educação (MEC) deixará de investir mais de R $\$ 300$ bilhões com a vigência da EC 95. E esse impacto será sentido nos Estados, DF e Municípios, que deixarão de contar com recursos de inúmeros convênios firmados com a esfera federal para financiar suas políticas de educação básica.

Portanto, o caminho para a privatização indiscriminada da educação, nos níveis básico e superior, está aberto com o ajuste fiscal promovido pela EC 95, além de outras políticas restritivas de direitos, como a inobservância deliberada do MEC às metas do PNE. Mas não é só isso!

Em 2015, o Supremo Tribunal Federal (STF) julgou constitucional a Lei 9.637/98, autorizando as escolas públicas a serem geridas por Organizações Sociais (OSs), retirando, assim, a exclusividade do Poder Público em administrá-las. Já em 2017, a Terceirização indiscriminada (Lei 13.429) e a Reforma Trabalhista (Lei 13.467), aliada à Lei das OSs, avança em inúmeras formas de contratos precários que poderão atingir todos os profissionais da educação escolar pública (professores, pedagogos e funcionários administrativos).

Essa "nova" estrutura organizacional e de contratação de pessoal imposta à escola pública brasileira, além de estimular a terceirização de sua gestão para políticos-empresários que atuam na área educacional através de OSs, também remontará a nefasta prática do nepotismo e de contratações políticas que a Constituição Federal de 1988 tinha conseguido estancar. Um retrocesso sem precedentes!

E, dado sequência à pavimentação da privatização e mercantilização da educação no nível básico, a "reforma" do Ensino Médio (Lei 13.415) visa a criar reserva de mercado para as empresas educacionais especializadas na Educação Profissional, visto que mais da metade do currículo escolar desta etapa poderá ser destinada às áreas de formação específica, com preponderância para a educação técnica e profissional aos estudantes das classes populares.

Por outro lado, o enfoque da "reforma" na formação técnica e profissional no ensino médio revela outro crime do governo golpista, que é de retirar - via formação menos qualificada para a aprovação nos exames de acesso às universidades - as chances dos jovens menos abastados (estudantes das escolas públicas) de poderem acessar a graduação em instituições públicas. Verdadeira engenharia de restrição de direitos!

\section{A privatização da educação através de parcerias público-privadas}

As parcerias público-privadas (PPPs) estão inseridas no contexto das reformas neoliberais do Estado brasileiro, empreendidas na década de 1990. Um dos principais diplomas legais sobre o tema refere-se à Lei Federal n. 8.987, de 1995, que dispõe sobre 
o regime de concessão e permissão da prestação de serviços públicos previsto no art. 175 da Constituição Federal. Junta-se a essa regulamentação, a Lei n. 9.074/95, que estabelece normas para outorga e prorrogações das concessões e permissões de serviços públicos; a Lei n. 9.637/98, que dentre outras finalidades dispõe sobre a qualificação de entidades como Organizações Sociais para atuar na educação e em outras áreas de interesse público; a Lei n. 9.790/99, que trata da qualificação de pessoas jurídicas de direito privado, sem fins lucrativos, como Organizações da Sociedade Civil de Interesse Público (OSCIP); a Lei n. 11.079/04, que instituiu normas gerais para licitação e contratação de parceria público-privada no âmbito da administração pública; a Lei 12.101/09, que criou o Certificado de Entidades Beneficentes de Assistência Social (Cebas), entre outras.

Na educação, as PPPs têm por objetivo redimensionar o financiamento e a gestão escolar e dos sistemas de ensino, criando mecanismos de competição por recursos públicos pautados especialmente em resultados de proficiência dos estudantes em testes nacionais. Ademais, elas introduzem métodos de gestão empresarial nas escolas, visando padronizar o aprendizado estudantil por meio de competências curriculares.

Com esse modelo, observa-se um deslocamento das responsabilidades do Estado para a iniciativa privada. A educação pública passa a ser entendida como um serviço não-exclusivo do Estado, operando-se um processo "natural" de transformação dos bens públicos em mercadoria.

E o resultado é que os direitos sociais são submetidos à lógica do mercado e a democracia não é mais uma comunidade de cidadãos portadores de direitos, mas uma sociedade de consumidores.

Essa ordem "democrática" do neoliberalismo, na verdade, busca legitimar a ideologia de mercado, sobrepondo o poder econômico das corporações às inúmeras atividades do Estado - inclusive na educação -, através da pseudo superioridade da gestão empresarial frente às administrações públicas "conservadoras", "burocráticas", "corruptas" e "ineficientes". Tais mitos, no entanto, escondem as falhas da gestão privada responsáveis pela quebradeira mundial nos séculos 20 e 21, assim como o sistemático aculturamento social, uma vez que os objetivos da "educação empresarial" não é formar cidadãos plenos de direitos e de oportunidades, mas, tão somente, trabalhadores comprometidos com a produtividade das empresas e com a manutenção de seus (sub)empregos.

Diante das experiências de PPPs em curso na educação brasileira, resumidamente, seus objetivos se pautam, por parte dos empresários, na captura de fundos públicos e na expansão das vagas privadas através de financiamento público direto às instituições particulares, e, por parte dos governos, numa economia fiscal a ser aferida com a redução de gastos diretos com a manutenção de escolas e com a folha de salários da educação pública, sendo que esta última rubrica ainda propiciará margem aos governos nos limites prudenciais da Lei Complementar n. 101/2000 (Lei de Responsabilidade Fiscal - LRF). 
Isso porque a contratação de pessoal terceirizado por meio de OSs não tem sua despesa vinculada aos limites da LRF.

Outra externalidade negativa se pauta no objetivo central das parcerias públicoprivadas, qual seja, a conformação da qualidade da educação aos processos de avaliações externas. Os testes nacionais, infelizmente, têm promovido e incentivado políticas educativas de caráter gerencialista, meritocrático e punitivo. As avaliações exigem competências e habilidades voltadas para a reestruturação produtiva, sendo que o Estado passa de um papel executor para outro de mero avaliador e controlador de políticas e serviços públicos.

Assim sendo, a responsabilidade do Estado em garantir uma educação pública de qualidade é repassada para os entes privados, sem nenhuma discussão sobre os prejuízos para a política educacional. As "entidades parceiras" acabam gerenciando a educação e definindo a linha pedagógica, a proposta de formação dos professores e até mesmo a avaliação dos resultados a partir de uma visão empresarial, desassociada das opiniões da comunidade escolar, pais, alunos, trabalhadores em educação e sociedade em geral. E sucumbe-se, assim, o direito constitucional à gestão democrática (art. 206, VI da Constituição).

\section{Números da privatização da educação básica no Brasil}

Em junho de 2017, a CNTE, em parceria com a Universidade de Brasília (UnB), lançou o livro "Privatização e Mercantilização da Educação Básica no Brasil”, abordando as contradições do financiamento público educacional no País, especialmente após a aprovação da EC 59, que ampliou a obrigatoriedade do ensino de 4 a 17 anos. Essa conquista social, que situa o Brasil entre as nações que mais asseguram o ensino obrigatório no mundo, fez, contudo, despertar o apetite privado em todas as etapas da educação básica.

No caso da educação infantil e da educação especial, ambas contam com condições excepcionais de repasse de verba pública para instituições comunitárias, confessionais ou filantrópicas sem fins lucrativos e conveniadas com o poder público, através do Fundo de Manutenção e Desenvolvimento da Educação Básica e de Valorização dos Profissionais da Educação (Fundeb).

$\mathrm{O}$ art. 213 da CF abre considerável flanco para diferentes formas de privatização da educação, inclusive por meio de parcerias público-privadas. $\mathrm{O}$ caput e seus incisos limitam o repasse de verbas públicas para instituições sem fins lucrativos, porém os parágrafos $1^{\circ}$ e $2^{\circ}$ do artigo constitucional possibilitam financiar todo tipo de instituição privada, com ou sem fins lucrativos.

Já o parágrafo $4^{\circ}$ do art. $5^{\circ}$ da Lei 13.005, que aprovou o PNE 2014/2024, contabiliza como investimento público em educação os recursos aplicados na forma do art. 212 da CF e do art. 60 do ADCT/CF. Também são contabilizados como investimento os recursos 
aplicados em programas de expansão da educação profissional e superior na forma de incentivo e isenção fiscal, como as bolsas de estudos concedidas no Brasil e no exterior, os subsídios a programas de financiamento estudantil e o financiamento de creches, pré-escolas e de educação especial na forma da CF .

O avanço crescente das políticas de privatização e mercantilização da educação no Brasil e no mundo afora está no rol das principais preocupações da CNTE e da Internacional da Educação (IE), entidade à qual a CNTE é filiada. Coube à IE organizar um levantamento mundial acerca da temática, por meio de suas quase 400 entidades filiadas em 170 países e territórios no mundo inteiro.

No âmbito da Resposta Mundial pretendida pela IE, algumas perguntas sobre o processo de mercantilização e privatização da educação no Brasil precisavam ser respondidas pela CNTE, enquanto entidade que representa mais de 4,5 milhões de educadores/ as no País. Com base nos dados disponíveis em relatórios, pesquisas e demais registros do Poder Público, bem como em informações coletadas junto às entidades de base de representação de professores/as e funcionários/as de escolas públicas da educação básica brasileira, a pesquisa se debruçou sobre as seguintes questões:

» A educação básica pública tem sido objeto de privatização? Em que medida isto vem acontecendo?

» Que elementos podem ser entendidos como FAVORECEDORES e FOMENTADORES desses processos de privatização da educação básica pública no Brasil?

» Na execução dos orçamentos dos entes federados, como são destinados os recursos à educação básica pública? Quem são os verdadeiros beneficiários nessa disputa de alocação de recursos? Quais são os projetos financiados com verbas públicas? A que fim serve a transferência de recursos públicos para educação no Brasil hoje?

O objetivo da CNTE com esta pesquisa, na condição de entidade de representação dos trabalhadores/as em educação, frente ao crescente processo de mercantilização a que a educação está submetida, visa investigar e mapear os elementos que levam a esse descaminho. Como anda, no Brasil, o processo de mercantilização e privatização da educação básica, o financiamento direto e indireto para a educação privada - que se refere, a rigor, à arena de disputa na alocação de recursos orçamentários para o setor da educação - e a atuação contundente de grupos econômicos interessados em abocanhar os recursos educacionais?

Para responder a essas questões, a CNTE resolveu buscar parceria com uma equipe de pesquisadores da Universidade de Brasília (UnB), a fim de investigar os elementos capazes de revelar a disputa por recursos públicos levada a cabo por grupos econômicos da educação privada. Para dar conta dos questionamentos, os pesquisadores assumiram 
a empreitada a partir de um conjunto de premissas e diretrizes de pesquisa que, de antemão, pudessem indicar a metodologia assumida na investigação:

I. Análise das matriculas da educação básica nos últimos três anos, com corte de matrícula e instituição pública e privada, analisando seus componentes, descrevendo tendências e comportamentos.

II. Investigação dos orçamentos públicos federal e estaduais e dos componentes de privatização dos gastos orçamentários em educação.

III. Pesquisa sobre o financiamento federal direto - recursos públicos transferidos às instituições de educação privadas para a oferta de serviços educacionais na educação básica.

IV. Mensuração do financiamento indireto da educação privada por meio de renúncias fiscais concedidas aos grupos privados de educação, por meio de Certificado de Entidades Beneficentes de Assistência Social (Cebas).

V. Realização de entrevistas com dirigentes públicos municipais e estaduais da educação para compreender como esses atores percebem o processo de mercantilização e privatização da educação.

Os resultados obtidos pela pesquisa são dignos da preocupação de todos que lutam por uma educação pública, gratuita, de boa qualidade e socialmente referenciada. Isso porque foram detectados os movimentos privatistas que permeiam silenciosamente as ações políticas e governamentais daqueles atores que, por determinação constitucional, têm como atribuição a gestão da educação pública brasileira. Ficou evidenciado que as ações privatistas contaminam as políticas públicas de gestão da educação pública em todos os níveis (federal, estaduais e municipais).

O conjunto de dados deve nos impelir a ações urgentes e necessárias em uma resposta direta às políticas de privatização da educação ora em curso no Brasil. Elas existem e já estão em estágio bem avançado. E, como no enigma da esfinge, estão a nos desafiar: decifra-me ou te devoro.

\section{Notas}

1 Anuário Brasileiro da Educação - 2017, p. 122-123. Consultado em 23/11/17. Disponível em: https://www. todospelaeducacao.org.br//arquivos/biblioteca/anuario_brasileiro_da_educacao_basica_2017_com_marcadores.pdf

2 Consultado em 23/11/17. Disponível em: http://www.cnte.org.br/images/stories/publicacoes/privatizacao_ mercantilizacao_educacao_basica_brasil.pdf 